\title{
Process of Identifying Stress Fields from Strain Fields in the Specimen with a Hole
}

\author{
Michaela Štamborská, ${ }^{1}$ Miroslav Kvíčala, ${ }^{2}$ and Vratislav Mareš ${ }^{1}$ \\ ${ }^{1}$ Department of Material Engineering, Faculty of Metallurgy and Materials Engineering, VŠB-Technical University of Ostrava, \\ 17. Listopadu 15, Poruba, 70833 Ostrava, Czech Republic \\ ${ }^{2}$ Department of Non-Ferrous Metals, Refining and Recycling, Faculty of Metallurgy and Materials Engineering, \\ VSB-Technical University of Ostrava, 17. Listopadu 15/2172, Poruba, 70833 Ostrava, Czech Republic
}

Correspondence should be addressed to Michaela Štamborská; stamborska.michaela@gmail.com

Received 16 July 2013; Accepted 16 September 2013

Academic Editors: Y. C. Lu and J. M. Prado

Copyright (C) 2013 Michaela Štamborská et al. This is an open access article distributed under the Creative Commons Attribution License, which permits unrestricted use, distribution, and reproduction in any medium, provided the original work is properly cited.

\begin{abstract}
The paper is focused on the process of identifying stress fields from strain fields in the specimen with a hole. The experiment was realized on the specimen with a hole made from anisotropic material. The main attention is paid to the analysis of deformation in the areas of stress (near the hole). That geometry generates a heterogeneous strain field which has been measured during the test using a digital image correlation system. The advantage of using heterogeneous strain fields in the identification procedure is that a complex state of stress-strain can be analyzed at the same time. On the other hand the stress field cannot be directly computed from the test and a suitable identification procedure has to be developed. Here, the virtual fields method (VFM) adapted for plastic strain has been used to identify the hardening behaviour and the anisotropy of the material. The values obtained by the VFM have been compared with the results coming from a standard identification made with uniaxial tensile tests.
\end{abstract}

\section{Introduction}

In sheet metal forming an anisotropic behaviour of sheet metals is often observed when they undergo plastic deformation. Such anisotropy is due to the rolling process which introduces anisotropy in the texture of the material. The correct identification of the plastic behaviour of anisotropic sheet metal is a very important aspect that has to be taken into account in order to enhance the results of the numerical models.

Traditionally the identification is carried out using uniaxial tensile tests performed at different directions respect to the rolling one. However in recent years, thanks to the development in the full-fields measurement techniques, more complex specimens which generate heterogeneous stressstrain fields can be used to study the behaviour of the material during the plastic flow.

The parameters can be then identified using for instance an inverse approach which includes the finite element (FE) updating [1-3].

Another identification procedure is the virtual fields method (VFM) [4] which has been successfully applied in many applications, including elastoplasticity $[5,6]$ and large strain plasticity [7].

The paper is focused on the process of identifying stress fields from strain fields in the specimen with a hole [8-10]. The main attention is paid to the analysis of deformation in the areas of stress (near the hole) [11-14]. The displacement and strain fields were measured using a stereocorrelation technique and the results have been used to identify the parameter with VFM. The Hill48 yielding criterion and the Swift hardening law were used as plasticity model.

The mentioned methods are applied to evaluate the properties of rolled sheets used for automotive production. The uncoated IF steel sheet was used for analysis (interstitialfree (IF)).

\section{Geometry and Parameters of Specimen}

This section assesses the properties of cold-rolled sheet metals used in pressing car body parts. A specimen with a hole and the geometry and the dimensions in millimetres as shown in 


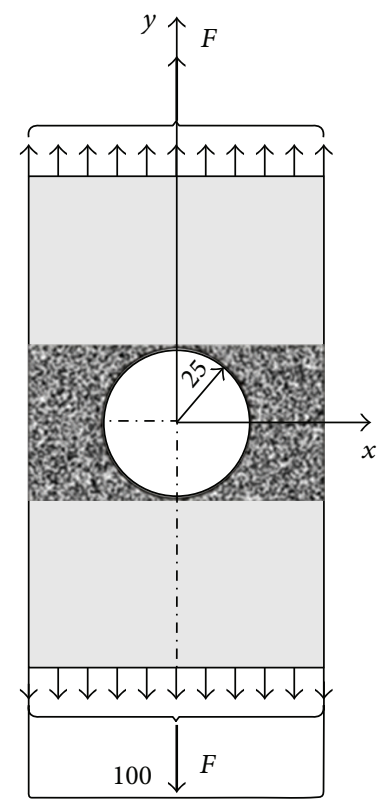

FIGURE 1: The geometry and dimensions $(\mathrm{mm})$ of specimen with a hole.

TABLE 1: The mechanical properties of the specimen.

\begin{tabular}{lcccccc}
\hline Dir. & $\begin{array}{c}\text { Thick. } \\
(\mathrm{mm})\end{array}$ & $\begin{array}{c}\text { Rp0,2 } \\
(\mathrm{MPa})\end{array}$ & $\begin{array}{c}\mathrm{Rm} \\
(\mathrm{MPa})\end{array}$ & $\begin{array}{c}\text { A80 } \\
(\%)\end{array}$ & $r$ & $n$ \\
\hline $0^{\circ}$ & 0,75 & 124 & 297 & 44,5 & 1,7 & 0,25 \\
$45^{\circ}$ & 0,75 & 139 & 305 & 42 & 1,6 & 0,23 \\
$90^{\circ}$ & 0,75 & 132 & 290 & 43,5 & 2,3 & 0,24 \\
\hline
\end{tabular}

Figure 1 was chosen for the deformation analysis. Further in the paper the term anisotropic material will refer to a sheet metal material that is anisotropic in plastic deformation.

Table 1 shows the specimen material's mechanical properties as demonstrated in tensile tests in the direction of sheet metal rolling. The values obtained by experiment are shown for the rolling direction $\left(0^{\circ}\right)$.

The specimen was made of DC06 sheet metal of extra deep drawn steel with classic high values of normal anisotropy coefficient $r$, which is suitable for the production of stampings of complex shapes [15].

To measure the specimen with a hole, a cross-beam displacement of $0.01 \mathrm{~mm} /$ image was set for the first ten steps, a displacement of $0.1 \mathrm{~mm} /$ image for the next ten steps, and a displacement of $0.2 \mathrm{~mm} /$ image from step 20 until the specimen broke apart (Figure 2). Please note that in this chart the elastic area is divided into several steps so it is clearer. The maximum cross-beam displacement was $20 \mathrm{~mm}$, which corresponds to a maximum force of $F_{\max }=10,280 \mathrm{~N}$.

\section{Results and Discussion}

3.1. Analysis of Strain Fields Using Digital Image Correlation. The results were visualised for a cross-beam displacement of $3.8 \mathrm{~mm}$ using the Vic 3D software.

Figure 3 shows the strain fields $\varepsilon_{x}, \varepsilon_{y}$, and $\gamma_{x y}$ as obtained in measurements for the specimen with a hole (Table 1) and processed with Vic 3D.

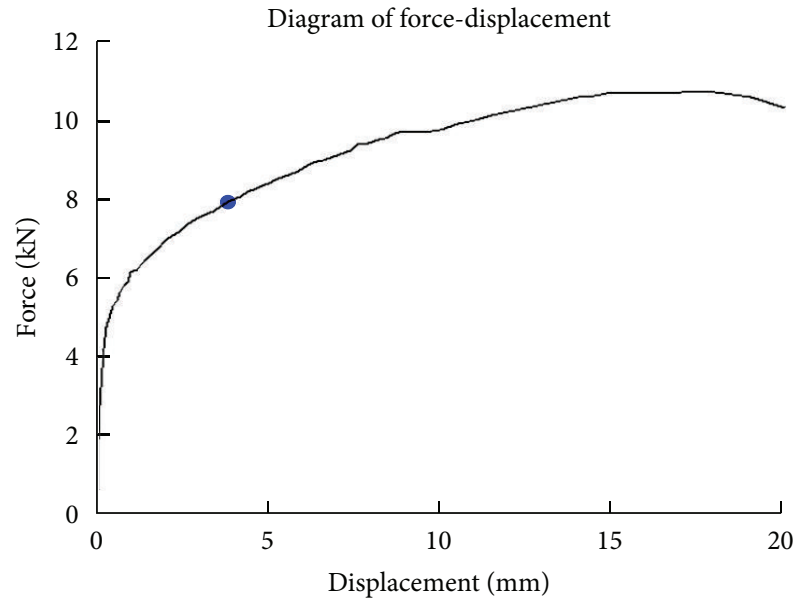

FIgURE 2: Diagram of force and cross-beam displacement for specimen with a hole.

3.2. Processing Results with Camfit. Program Camfit is a GUI MATLAB-based software that implements the virtual fields method. It can deal with linear elasticity (isotropic and orthotropic) as well as simple elastoplasticity. Camfit's purpose is to process the displacement fields measured using the virtual fields method. The theoretical basis of the virtual fields method can be found in the literature [4-6].

The values of the displacement fields $u_{x}$ and $u_{y}$ and the force values corresponding to each picture were exported from Vic 3D. The mask and the grid size were selected after loading values.

For reasons of task symmetry, the area shown along with the grid in Figure 4 was chosen for the specimens with a hole (Figure 1).

Figure 5 shows displacement fields $u_{x}$ and $u_{y}$ for specimen with a hole as obtained in measurements with a 


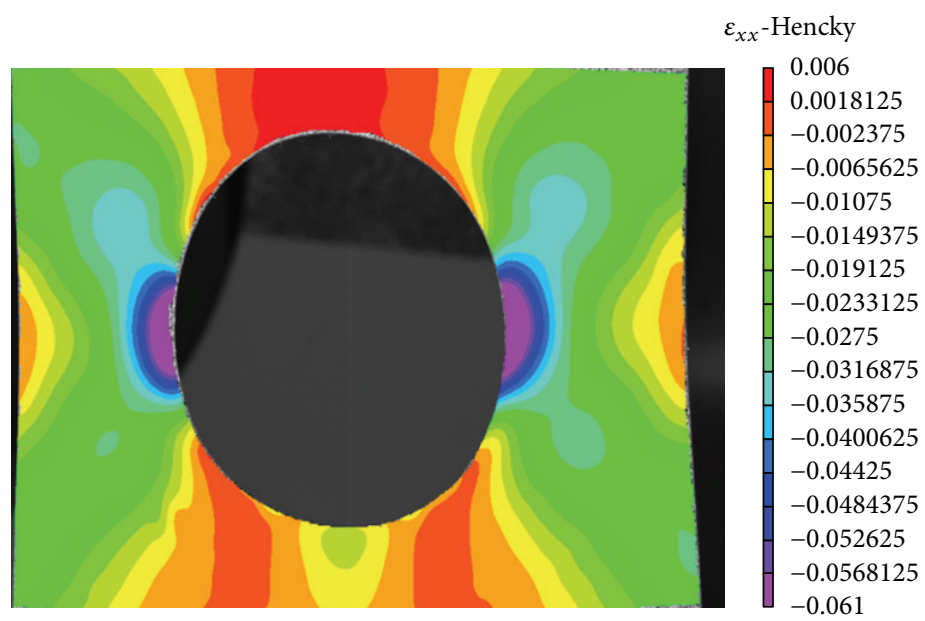

(a)

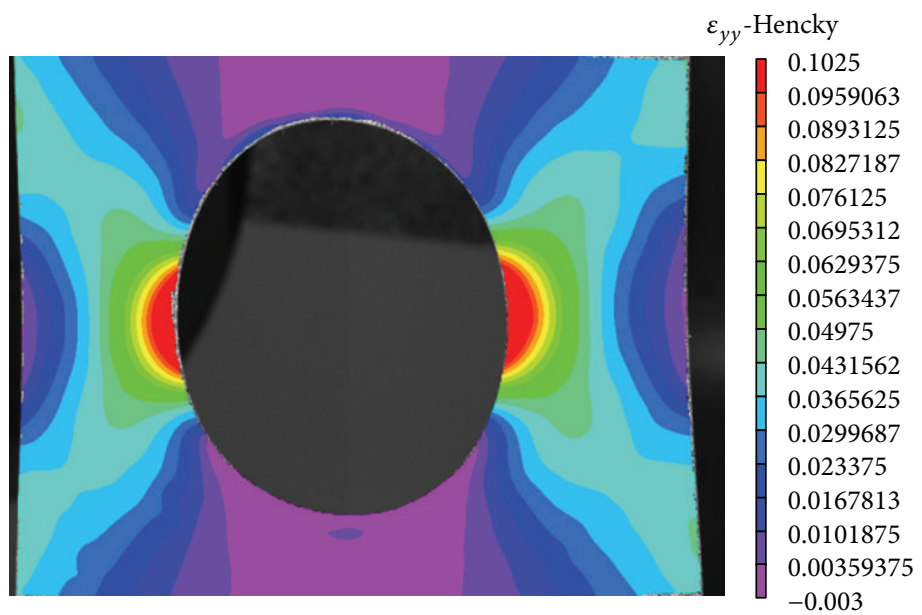

(b)

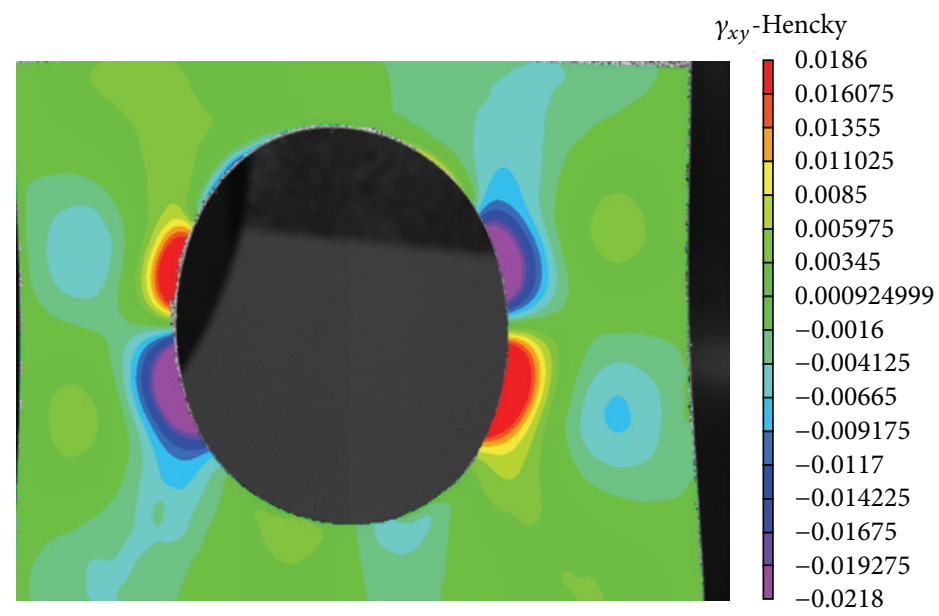

(c)

FIgURE 3: The contours of strain fields (a) $\varepsilon_{x}$, (b) $\varepsilon_{y}$, and (c) $\gamma_{x y}$ (-) obtained by Vic 3D for specimen with a hole. 


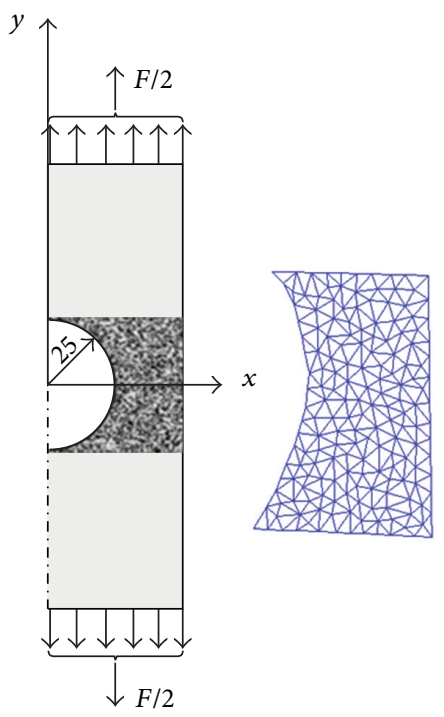

FIGURE 4: Grid chosen for specimens with a hole.

cross-beam displacement of $3.8 \mathrm{~mm}$. Figure 5(a) shows displacement fields $u_{x}$ and $u_{y}$ in the selected area and Figure 5(b) shows displacement fields $u_{x}$ and $u_{y}$ with the grid applied.

Figure 6 shows the strain fields $\varepsilon_{x}, \varepsilon_{y}$, and $\gamma_{x y}$ as obtained by Camfit for a cross-beam displacement of $3.8 \mathrm{~mm}$. The results can be compared with results obtained by Vic $3 \mathrm{D}$ (Figure 3).

In elastoplasticity range, Camfit uses only one constant virtual strain field, and as defined in the previous text, it depends on the test configuration. This can also be seen as the difference between averages, normal or shear force, measured and recalculated from the strains, and the constitutive parameters. The program first identifies the isotropic elastic constants (Young's modulus and Poisson's ratio) for specimen with a hole, as we can see in Figure 7. This enables us to define an elastic range for the test, thanks to a plot which reports external and internal virtual work. If linearity is correct, then the elastic area was well defined. Otherwise, it should be changed to arrive to acceptable linearity.

The second stage concerns the plastic parameters and there are four isotropic hardening models, which are based on the simple Prandtl-Reuss model. In this case, the power law model was chosen and the results are shown in Figure 8.

The values $X_{1}, X_{2}$, and $X_{3}$ are obtained by Camfit for elastoplastic area in the whole process of the measurement. The other parameter, which can be determined in the elastoplastic area, is yield stress.

Comparing the results in figure and those in Table 1, it is clear that the yield stress obtained by Camfit for the elasticplastic area is, in essence, the same as the yield point obtained in a standardised tensile test. Other parameters of sheet metal material properties obtained in elastic-plastic strain shown in figure are the input data for identifying the stress fields in the elastic-plastic area.

3.3. Stress Fields Determination Using MATLAB. The parameters obtained by the Camfit program for the elastoplastic area were then processed in Matlab to compute stress fields $\sigma_{x}, \sigma_{y}$, and $\tau_{x y}$ for anisotropic material [16].

The chosen plastic model is the Hill48 yield criterion [17] with isotropic hardening. In the plane stress case, the Hill48 criterion can be written as

$$
\sigma_{\mathrm{eq}}=(g+h) \sigma_{x}^{2}-2 h \sigma_{x} \sigma_{y}+(f+h) \sigma_{y}^{2}+2 n \tau_{x y}^{2},
$$

where $f, g, h$, and $n$ are parameters which can be computed from the Lankford parameters at different orientations. If we assume that the equivalent plastic strain $\sigma_{\text {eq }}$ is equivalent to the yield stress in the rolling direction, that is, $0^{\circ}$, it can be shown that [18]

$$
\begin{gathered}
g=\frac{1}{1+R_{0}} ; \quad f=\frac{1}{1+R_{90}} ; \quad h=\frac{R_{0}}{1+R_{0}} ; \\
n=\left(\frac{1}{2}+R_{45}\right)\left(1+\frac{R_{0}}{R_{90}}\right) g
\end{gathered}
$$

where $R_{0}, R_{45}$, and $R_{90}$ are the values of the Lankford parameters measured at orientations $0^{\circ}, 45^{\circ}$, and $90^{\circ}$, respectively. The hardening law is described using the Swift law:

$$
\sigma_{\mathrm{eq}}=K \cdot\left(\varepsilon_{0}+\varepsilon_{\mathrm{eq}_{\mathrm{pl}}}\right)^{n}
$$

where $\varepsilon_{\mathrm{eq}_{\mathrm{pl}}}$ is the equivalent accumulated plastic strain, $K$, $\varepsilon_{0}$, and $n$ are the parameters to be identified by Camfit and denoted by $X_{1}, X_{2}$, and $X_{3}$.

The stress fields obtained from strain fields calculated by Matlab for specimen with a hole for displacement $3.8 \mathrm{~mm}$ are illustrated in Figure 9.

Table 2 shows the measurement results as obtained by Camfit. Classic standardised tensile tests (for two specimens) had been carried out prior to the experiment. The yield stress for the given material and the material properties obtained by these tests are shown in Table 1 . The results of yield stress 

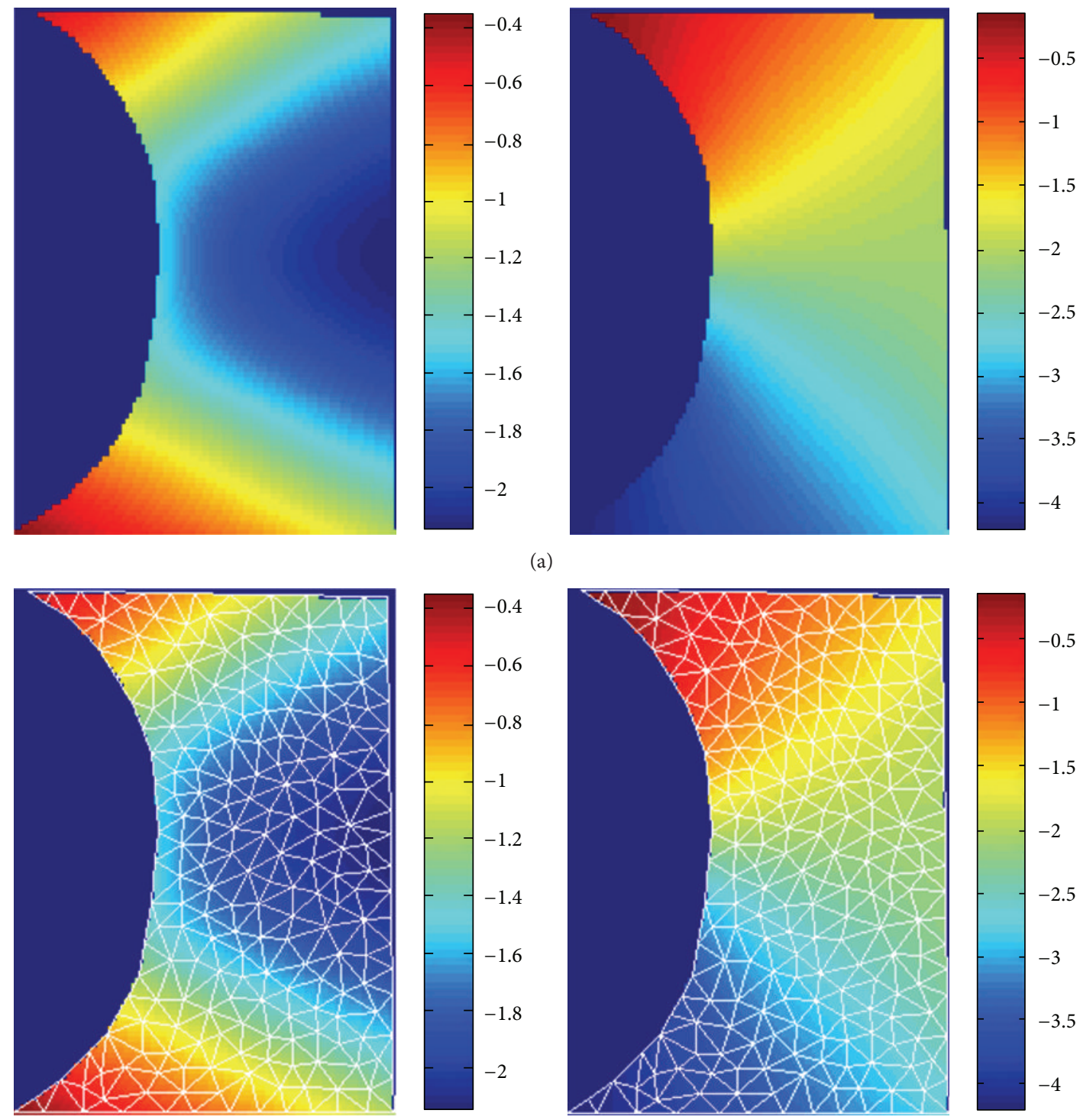

(b)

FIGURE 5: The displacement fields $u_{x}$ and $u_{y}$ for specimen with a hole.
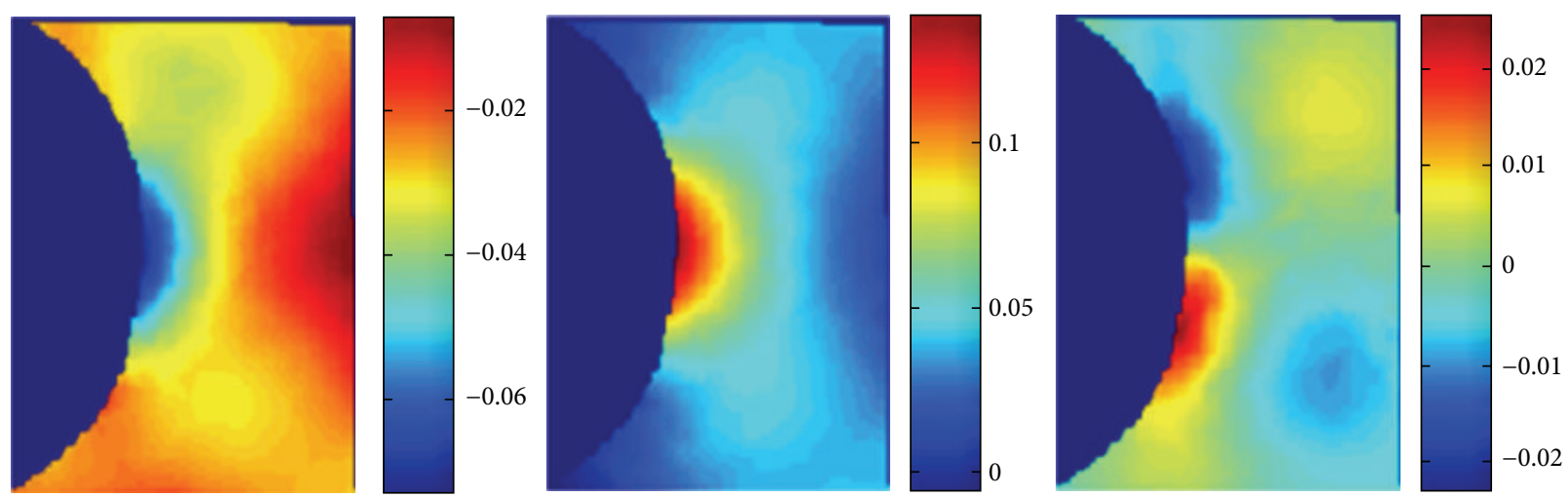

FIgURE 6: The strain fields $\varepsilon_{x}, \varepsilon_{y}$, and $\gamma_{x y}(-)$ obtained by Camfit for specimen with a hole. 
Young's modulus $=139.4 \mathrm{GPa}$

Poisson's ratio $=0.265$
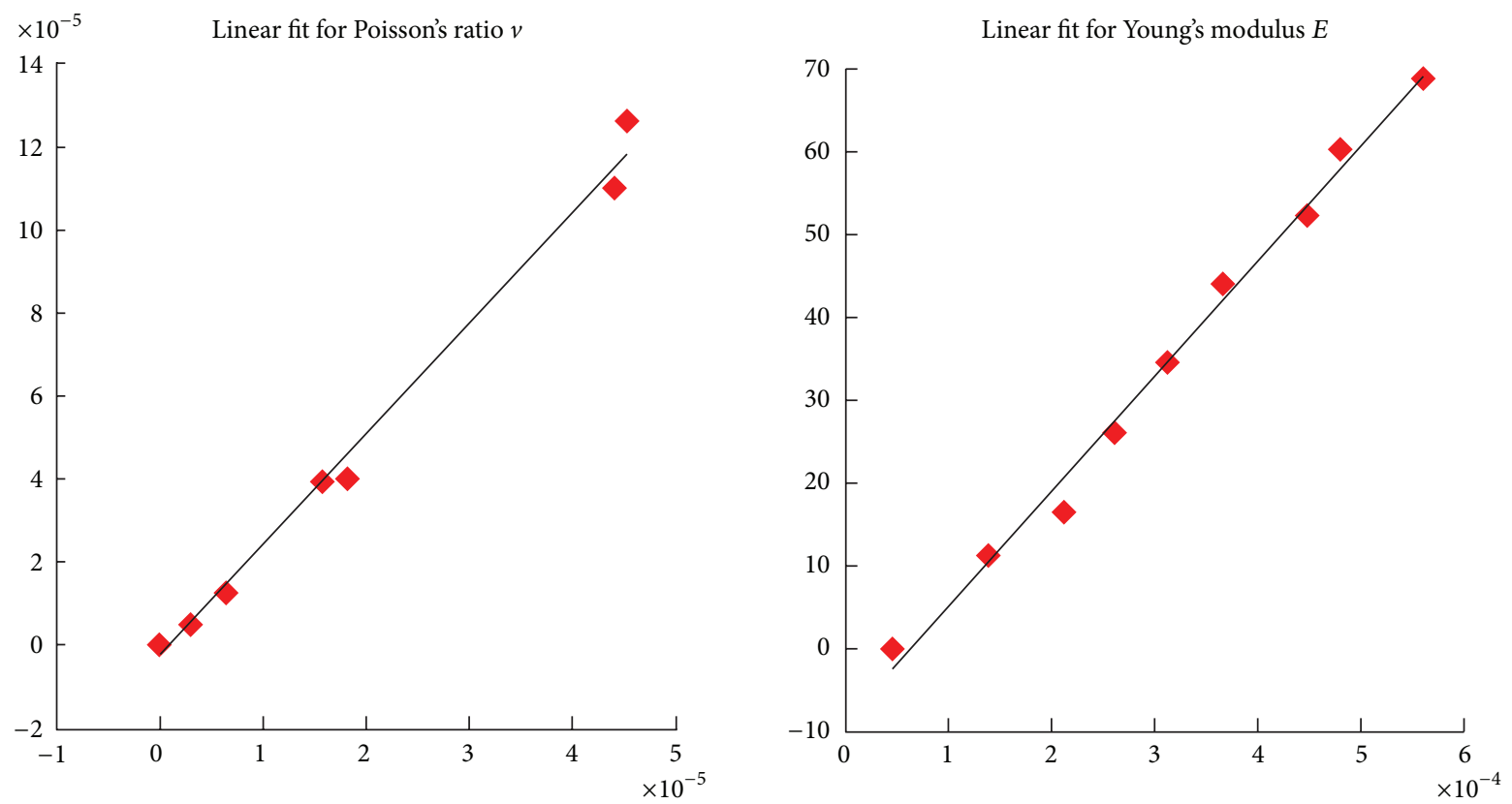

FIGURE 7: Identification of parameters in elastic area for specimen with a hole.

Young's modulus $=139.4 \mathrm{GPa}$

Poisson's ratio $=0.26$

Elastoplasticity with power law (s_eq $\left.=X_{1}{ }^{*}\left(\mathrm{ep}+X_{2}\right)^{X_{3}}\right)$

$X_{1}=1284.2 \mathrm{MPa}$

$X_{2}=0.008$

$X_{3}=0.478$

Initial yield stress $=125.7 \mathrm{MPa}$

Minimization: cost function $=62.734$; iterations $=50$

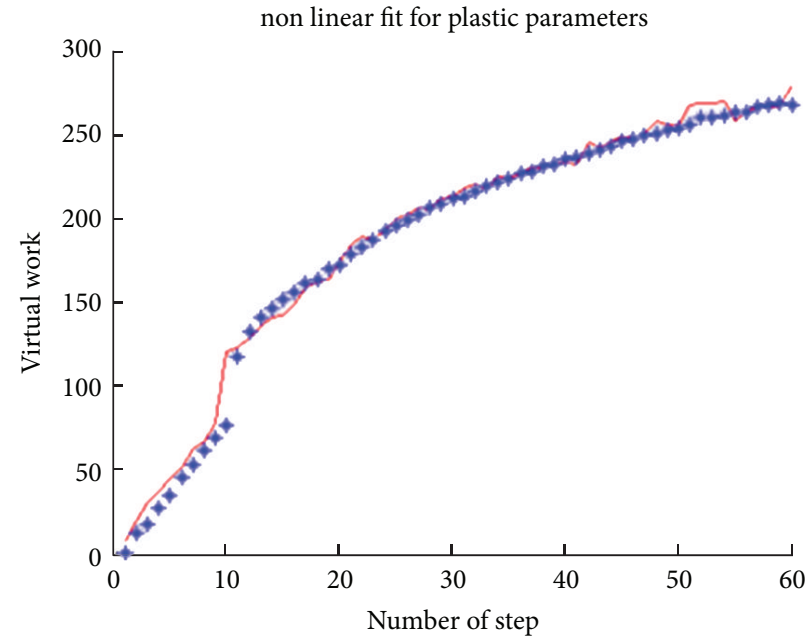

FIGURE 8: Parameters obtained in elastoplastic range by Camfit for specimen with a hole. 
TABLE 2: Results obtained by Camfit and standardised tensile test.

\begin{tabular}{lccccccc}
\hline & & \multicolumn{2}{c}{ Camfit } & \multicolumn{3}{c}{ Tensile test } \\
Parameters in elastic range & \multicolumn{2}{c}{ Parameters in elastoplastic range (power law) } & \multicolumn{2}{c}{ Yield stress } \\
$E[\mathrm{GPa}]$ & $\mu$ & $X_{1}$ & $X_{2}$ & $X_{3}$ & $R_{e}$ & Test1 \\
\hline 139,4 & 1284,2 & 0,008 & 0,478 & 125,7 & 124 \\
\hline
\end{tabular}
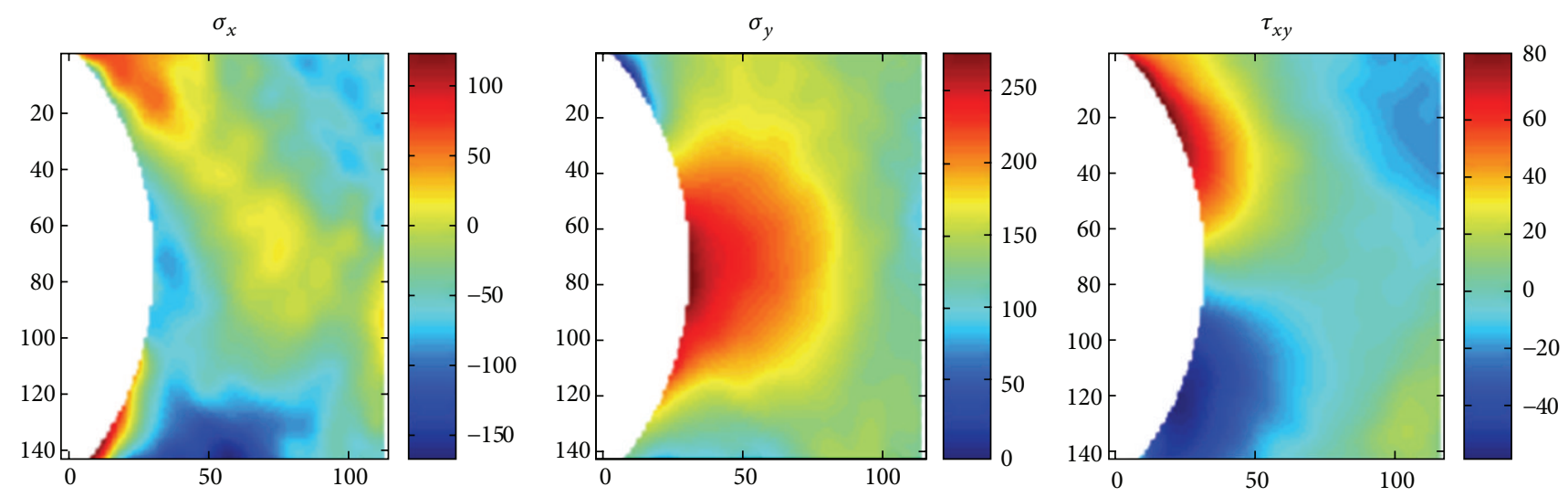

FIgURE 9: The stress fields $\sigma_{x}, \sigma_{y}$, and $\tau_{x y}$ MPa obtained from strain fields for specimen with a hole.

obtained by Camfit were compared with the results obtained in the tensile tests (Test1 and Test 2 in Table 2). Comparing the yield stress values obtained with Camfit and the yield stress values obtained in classic tensile tests shows a very good conformity, which proves the fact that the virtual fields method is suitable for determining material properties of sheet metal specimens.

\section{Conclusions}

The present paper is aimed at the process of identifying stress fields from strain fields in the specimen with a hole.

Digital image correlation (DIC) was used to analyze plastic strain development. DIC is one of the rapidly developing modern unconventional optical methods of experimental mechanics. The possibility of overall capture of the displacements on the surface of specimens permits a real picture to be obtained of how strain is distributed at the points of stress.

The material properties of the steel sheet metals used to produce specimens were obtained by standardised tensile tests and their values were compared with the results obtained by an experimental method of identifying sheet metal material properties. Camfit software was used in this experimental method and overall measurement was applied. Comparing the resultant values for the material's yield point shows a good conformity with the results obtained by Camfit, which uses the virtual work method to make calculations. The Camfit material parameters were then used in determining stress fields using the strain fields measured while applying hardening models suitable for isotropic materials. These methods enable the analysis of stress in the elastic and the plastic areas in tasks of concentrated stress while considering the material's anisotropy in plastic deformation.

This allows us to predict damage to thin-walled structural features primarily in the areas where stress may concentrate and serves as a basis for assessing the service time of such features and it provides information for the optimisation of the manufacturing of such features by sheet metal cold pressing.

\section{Conflict of Interests}

With all responsibility the authors would like to declare that non of them is financially supported by producers or distributors of commercial programmes MATLAB, Camfit, and Vic 3D. Moreover, they do not have any other kind of interest to propagate and support these commercial programmes. In the paper they were used as a necessary tool for their simulations.

\section{Acknowledgments}

This paper has been elaborated in the framework of the project Opportunity for young researchers, reg. no. CZ.1.07/ 2.3.00/30.0016, supported by Operational Programme Education for Competitiveness and cofinanced by the European Social Fund and the state budget of the Czech Republic and in the framework of the project Regional Materials Technology Research Centre (RMTVC) reg. no. CZ.1.05/2.1.00/01.0040.

\section{References}

[1] S. Cooreman, D. Lecompte, H. Sol, J. Vantomme, and D. Debruyne, "Elasto-plastic material parameter identification by inverse methods: calculation of the sensitivity matrix," International Journal of Solids and Structures, vol. 44, no. 13, pp. 4329-4341, 2007.

[2] H. Tao, N. Zhang, and W. Tong, "An iterative procedure for determining effective stress-strain curves of sheet metals," International Journal of Mechanics and Materials in Design, vol. 5, no. 1, pp. 13-27, 2009. 
[3] J. Kajberg and G. Lindkvist, "Characterisation of materials subjected to large strains by inverse modelling based on inplane displacement fields," International Journal of Solids and Structures, vol. 41, no. 13, pp. 3439-3459, 2004.

[4] M. Grédiac, F. Pierron, S. Avril, and E. Toussaint, "The virtual fields method for extracting constitutive parameters from fullfield measurements: a review," Strain, vol. 42, no. 4, pp. 233-253, 2006.

[5] M. Grédiac and F. Pierron, "Applying the virtual fields method to the identification of elasto-plastic constitutive parameters," International Journal of Plasticity, vol. 22, no. 4, pp. 602-627, 2006.

[6] F. Pierron, S. Avril, and V. T. Tran, "Extension of the virtual fields method to elasto-plastic material identification with cyclic loads and kinematic hardening," International Journal of Solids and Structures, vol. 47, no. 22-23, pp. 2993-3010, 2010.

[7] M. Rossi and F. Pierron, "Identification of plastic constitutive parameters at large deformations from three dimensional displacement fields," Computational Mechanics, vol. 49, no. 1, pp. 53-71, 2012.

[8] T. Cohen, R. Masri, and D. Durban, "Analysis of circular hole expansion with generalized yield criteria," International Journal of Solids and Structures, vol. 46, no. 20, pp. 3643-3650, 2009.

[9] V. G. Ukadgaonker and D. K. N. Rao, "A general solution for stresses around holes in symmetric laminates under inplane loading," Composite Structures, vol. 49, no. 3, pp. 339-354, 2000.

[10] K. Ting, K. T. Chen, and W. S. Yang, "Stress analysis of the multiple circular holes with the rhombic array using alternating method," International Journal of Pressure Vessels and Piping, vol. 76, no. 8, pp. 503-514, 1999.

[11] N. Troyani, C. Gomes, and G. Sterlacci, “Theoretical stress concentration factors for short rectangular plates with centered circular holes," Journal of Mechanical Design, vol. 124, no. 1, pp. 126-128, 2002.

[12] D. Durban and V. Birman, "On the elasto-plastic stress concentration at a circular hole in an anisotropic sheet," Acta Mechanica, vol. 43, no. 1-2, pp. 73-84, 1982.

[13] T. Iwaki, "Stress concentrations in a plate with two unequal circular holes," International Journal of Engineering Science, vol. 18, no. 8, pp. 1077-1090, 1980.

[14] G. B. Sinclair, "On the effect on stress concentration of rounding the edges of a hole through a plate," International Journal of Mechanical Sciences, vol. 22, no. 12, pp. 731-734, 1980.

[15] W. T. Lankford, S. C. Snyder, and J. A. Bausher, "New criteria for predicting the press performance of deep drawing sheets," Transactions of the American Society of Metals, vol. 42, pp. 11971232, 1950.

[16] M. Rossi, F. Pierron, M. Štamborská, and F. Šimčák, "Identification of the anisotropic plastic behaviour of sheet metals at large strains," Experimental and Applied Mechanics, vol. 4, pp. 229$235,2013$.

[17] R. Hill, "A theory of yielding and plastic flow of anisotropic metals," Proceedings of the Royal Society of London A, vol. 193, pp. 281-297, 1948.

[18] M. Rossi, G. B. Broggiato, and S. Papalini, "Application of digital image correlation to the study of planar anisotropy of sheet metals at large strains," Meccanica, vol. 43, no. 2, pp. 185-199, 2008. 

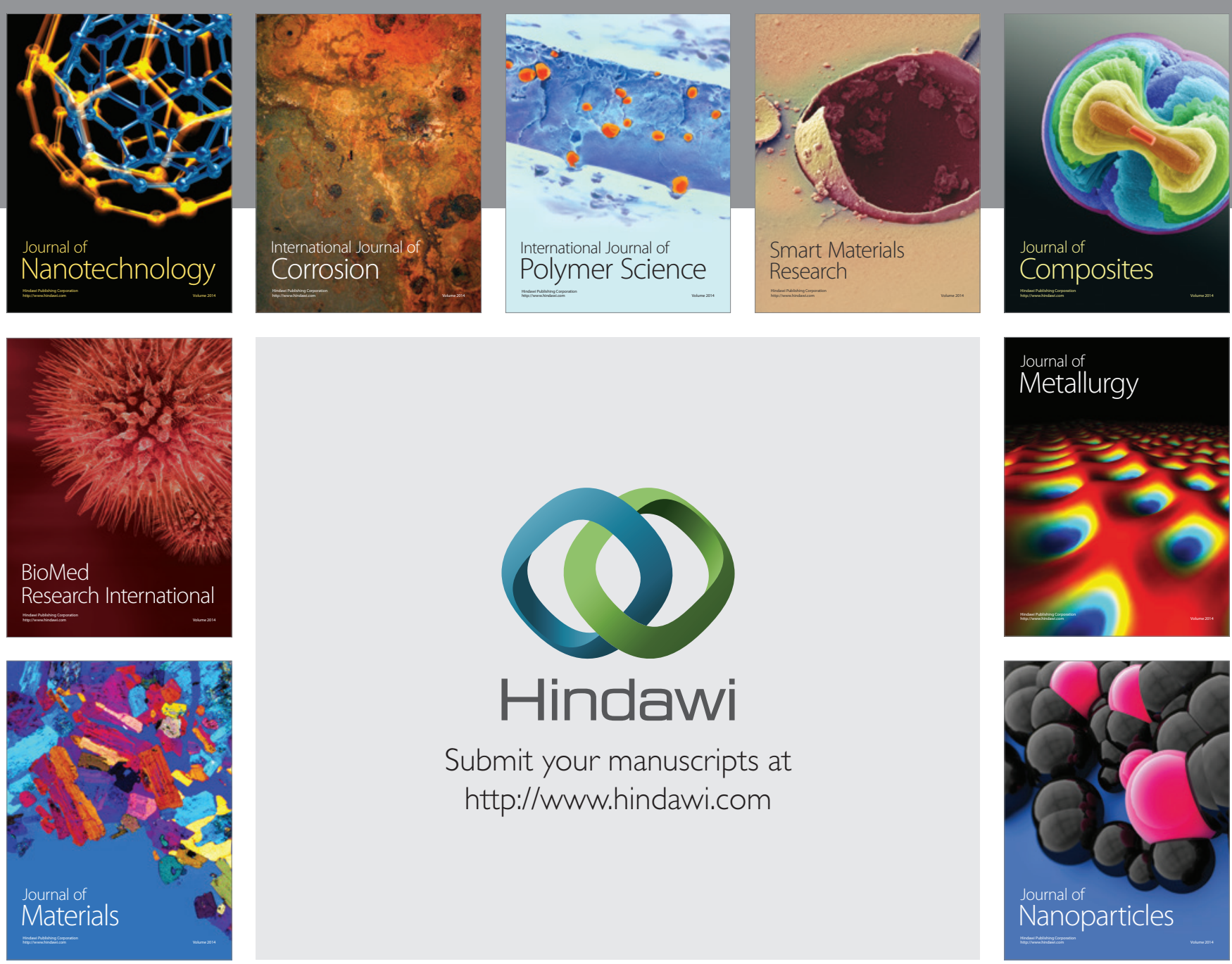

Submit your manuscripts at http://www.hindawi.com
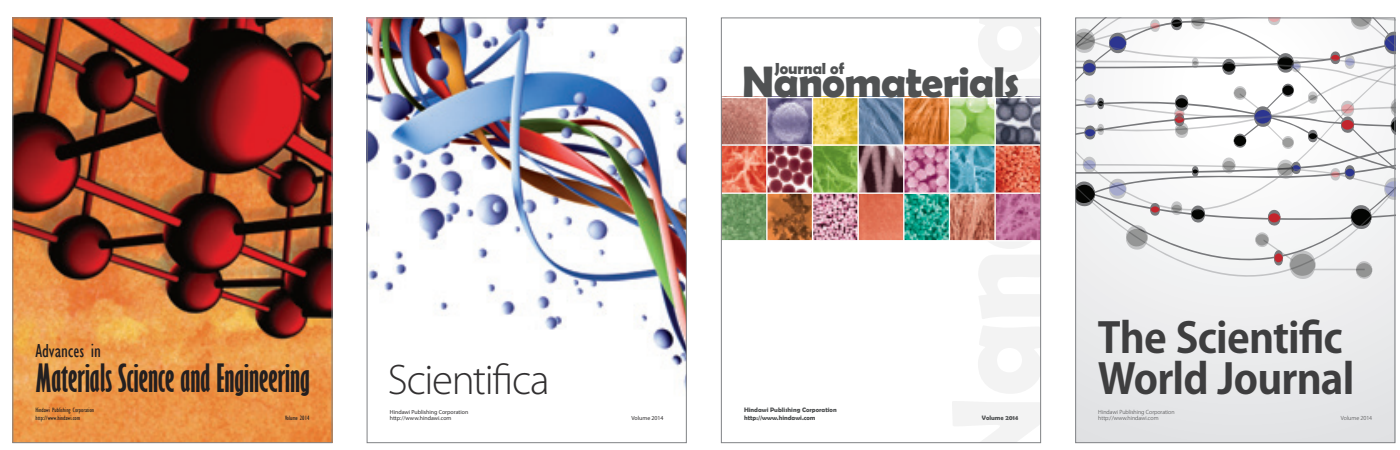

\section{The Scientific World Journal}
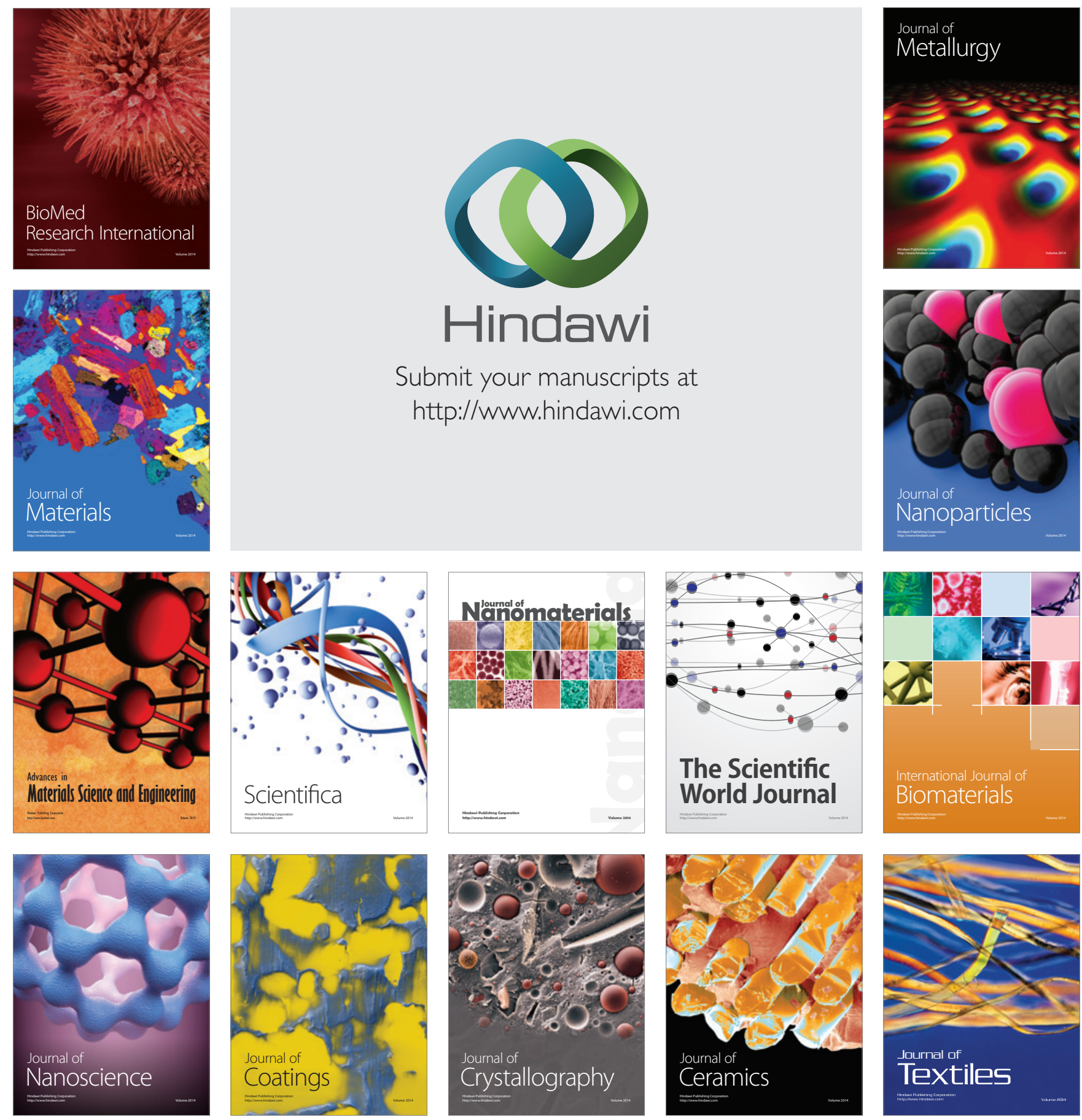